\title{
EVENTOS COMPORTAMENTAIS PRIVADOS
}

\author{
PRIVATE BEHAVIORAL EVENTS
}

\author{
JAY MOORE \\ UNIVERSITY OF WISCONSIN-MILWAUKEE, ESTADOS UNIDOS
}

\begin{abstract}
RESUMO
Eventos comportamentais privados são aqueles eventos nos quais a estimulação com relação à qual um indivíduo responde não é acessível do ponto de vista de outra pessoa. Nestes casos, a estimulação pode ser verbal ou não verbal. Além disso, as respostas em relação a essa estimulação podem ser verbais ou não verbais e acessíveis ou não a outros. Um tipo de evento privado envolve relatos verbais ocasionados por condições do corpo, tais como desconfortos ou dores. Um segundo tipo envolve comportamento operante encoberto, tal como pensamento, resolução de problemas e devaneio (daydreaming). Para cada tipo, uma explicação naturalística pode ser desenvolvida baseada em conceitos derivados da análise do comportamento aberto.
\end{abstract}

Palavras-chave: B. F. Skinner, eventos comportamentais privados, problema da privacidade, resolução de problemas, pensamento, relatos verbais.

\begin{abstract}
Private behavioral events are those events in which the stimulation with respect to which an individual responds is not accessible from the vantage point of another person. In such cases, the stimulation may be verbal or nonverbal. Further, the responses with respect to this stimulation may be verbal or nonverbal, and accessible or not to others. One type of private event involves verbal reports occasioned by conditions of the body, such as aches and pains. A second type involves covert operant behavior, such as thinking, problem solving, and daydreaming. For each type, a naturalistic account may be developed based on concepts derived from the analysis of overt behavior.

Key words: B. F. Skinner, private behavioral events, problem of privacy, problem solving, thinking, verbal reports.
\end{abstract}

\footnotetext{
Este artigo foi extraído do material que desenvolvi ao longo dos anos para ajudar nas minhas próprias atividades de ensino do tópico de eventos comportamentais privados em análise do comportamento. Eu ofereço-o aqui na esperança de que outros o acharão útil. Para ser condizente com o objetivo educativo do artigo, as referências são mínimas. Além disso, tanto a linguagem quanto o argumento são mais informais do que em outros artigos. Se eu deixei a desejar na execução, eu peço desculpas e a tolerância dos leitores. Eu só posso dizer que as contingências ainda não me finalizaram. Correspondência acerca do artigo devem ser destinadas ao autor em jcm@uwm.edu ou no seu endereço residencial: 1861 E. Fox Lane; Fox Point, WI 53217; USA.
}

Tradução: Luiz Alexandre Barbosa de Freitas (Professor Adjunto do Departamento de Psicologia da Universidade Federal de Mato Grosso. Discente do Programa de Pós-Graduação em Teoria e Pesquisa do Comportamento da Universidade Federal do Pará). 


\section{EVENTOS COMPORTAMENTAIS PRIVADOS}

Quando dizemos que respondemos com relação ao ambiente, geralmente estamos falando de um ambiente que é publicamente observável. Entretanto, em alguns casos, nós respondemos com relação à estimulação em uma parte do ambiente que não é acessível do ponto de vista de outros. Ao contrário, ela é acessível apenas a nós mesmos, por exemplo, porque está dentro da nossa pele. Estes casos podem ser chamados de "eventos comportamentais privados". Estas formas de estimulação podem ser verbais ou não verbais. Além do mais, as respostas que damos a tais estimulações podem ser verbais ou não verbais, e também observadas e acessíveis a outros ou não observadas e inacessíveis. Este artigo busca descrever a natureza e a importância desses eventos comportamentais privados para uma compreensão do comportamento (e.g., Skinner, 1953).

\section{DOIS TIPOS DE EVENTOS COMPORTAMENTAIS PRIVADOS}

Vamos começar identificando os dois tipos de eventos comportamentais privados. O primeiro tipo envolve os eventos que ocorrem quando aprendemos a falar sobre nossas sensações e sentimentos, como quando falamos sobre nossos desconfortos e dores. O segundo tipo envolve os eventos que ocorrem quando formas encobertas de comportamento se desenvolvem e nos influenciam, como quando pensamos e resolvemos problemas. Ambos os tipos de eventos privados ocorrem com bastante frequência e cabe a uma ciência do comportamento explicá-los de formas naturalísticas. Podemos fazê-lo usando os mesmos termos e conceitos analíticos e explanatórios que usamos para explicar eventos comportamentais públicos.

Eventos Comportamentais Privados do Primeiro Tipo: Relatos Verbais Sobre Nossas Sensações e Sentimentos

O que sentimos são condições internas nos nossos corpos. Essas condições surgem durante o processo viver, por exemplo, à medida que nosso processo metabólico ocorre ou quando entramos em contato com eventos ambientais, variáveis e relações. Por sua vez, entramos em contato com essas condições internas através do nosso sistema nervoso interoceptivo e, possivelmente, proprioceptivo. A questão importante aqui se refere a como aprendemos a falar significativamente sobre essas condições internas. Uma reflexão momentânea nos diz que essa questão é importante para pais que querem encorajar seus filhos a falar sobre seus desconfortos e dores ("Onde está doendo?"), para que assim os pais possam atenuar os problemas de seus filhos.

Começamos nossa resposta observando que relatos verbais ocasionados por nossas sensações e sentimentos são respostas operantes. Respostas operantes ocorrem por causa das contingências: a relação sistemática entre estímulo discriminativo antecedente, a resposta e a consequência reforçadora da resposta. Comportamento verbal de qualquer tipo se desenvolve e é mantido por meio do reforçamento diferencial realizado pela comunidade verbal.
Considere como a comunidade verbal ensina crianças a dizer que os frutos do açaí são roxos. Aqui, os frutos roxos são públicos e diretamente acessíveis a ambos, à comunidade verbal e à criança. A comunidade verbal pode reforçar a resposta da criança de dizer "roxo" na presença do fruto roxo do açaí e não qualquer outra coisa.

Uma reflexão momentânea sugere que as circunstâncias são diferentes quando a comunidade verbal ensina as crianças a dizerem que elas sentem dor. Aqui, a comunidade verbal não está em contato direto com uma condição interna como a ocasião para reforçar diferencialmente o falar sobre isso, de maneira que a condição prontamente adquira o controle de estímulos necessário para falarmos significativamente sobre isso. Esse obstáculo é chamado de “o problema da privacidade". Deste modo, a questão de como o comportamento verbal sobre nossas condições internas se desenvolve representa um problema relativo a como o controle de estímulos apropriado se desenvolve sobre o comportamento verbal quando as circunstâncias discriminativas são privadas. No entanto, as crianças obviamente aprendem a falar, pelo menos um tanto significativamente, sobre suas condições internas. Seguese, então, que a comunidade verbal trabalha em torno deste obstáculo. A questão relevante é: como isso acontece?

A comunidade verbal contorna o problema da privacidade usando circunstâncias públicas correlacionadas com as privadas, que são a condição interna de base para realizar o reforçamento diferencial necessário. Um caso envolve nossas "respostas colaterais". Quando crianças se machucam ou quando têm um desconforto ou uma dor, eles podem tocar, massagear ou segurar a área afetada. Se a perna dói, elas podem mancar. Se as costas estão doloridas, elas podem andar arqueadas, com uma postura encurvada. Se o dente dói, elas podem segurar a mandíbula. Os comportamentos delas de tocar, massagear ou segurar a área afetada, ou de andar mancando ou encurvadas, constituem a "resposta colateral". Nessas ocasiões, e não em outras, a comunidade verbal reforça falas da criança de que está sentindo dor (e.g. pelo menos através da aprovação, compreensão e simpatia, se não também por atenção para aliviar a dor).

Um segundo caso envolve "acompanhamentos públicos". Quando crianças são espetadas por um objeto pontiagudo, a comunidade verbal a encoraja a dizer que tem uma "dor aguda". Quando crianças são atingidas por um objeto maciço, a comunidade verbal as encoraja a dizer que têm uma "dor maciça". Quando crianças se queimam em um fogão quente, a comunidade verbal as encoraja a dizer quer têm uma "dor ardente". Ser espetado pelo objeto pontiagudo, atingido pelo objeto maciço ou tocar o fogão quente constituem os "acompanhamentos públicos", e a comunidade verbal reforça diferencialmente a fala das crianças de terem sentido dor, e presumivelmente não o faz em outras ocasiões. Além disso, a comunidade verbal frequentemente encoraja a fala das crianças sobre qualidades particulares daquela dor, tão somente como um tipo de relação metafórica, como em 
aguda, maciça e ardente. Os pais encorajam seus filhos a falar de tais dores porque poderão então aliviá-las ou mesmo porque poderão agir para prevenir que seus filhos se machuquem e experimentem essas dores no futuro.

Vemos que, quando respostas colaterais e acompanhamentos públicos estão envolvidos, a comunidade verbal reforça diferencialmente falantes quando estimulações públicas e privadas estão presentes. A estimulação pública são as respostas colaterais e o acompanhamento público, e a estimulação privada são as condições internas que surgem por meio dos processos de viver e interagir com o ambiente. Porque tanto a estimulação pública quanto a privada estão presentes, ambas adquirem controle de estímulos. Posteriormente, os indivíduos são capazes de falar sob controle discriminativo apenas da estimulação privada advinda da condição interna quando ela ocorrer, mesmo que correlatos públicos na forma de respostas colaterais ou acompanhamentos públicos não estejam envolvidos.

Podemos interromper aqui para observar que alguns indivíduos aprendem a explorar os processos descritos acima. Os termos malingerers ${ }^{1}$ (malandro ou fingido) e hipocondríaco são às vezes aplicados a esses indivíduos. Esses indivíduos fazem afirmações aparentemente sobre uma condição interna debilitante como desconfortos ou dores porque ao fazê-lo os indivíduos escapam de uma situação aversiva ou ganham algum benefício - pelo menos a atenção de outros - ao invés de porque seu comportamento verbal está sob controle discriminativo de alguma condição de estímulo interna que esteja verdadeiramente presente. Os indivíduos são posteriormente revelados como malingerers ou hipocondríacos quando não observamos respostas colaterais ou acompanhamentos públicos que estão geralmente correlacionados com essas afirmações.

Um terceiro caso de evento comportamental privado é uma extensão dos dois casos - respostas colaterais e acompanhamentos públicos - tratados acima. Este terceiro caso envolve generalização de estímulos. Aqui, depois que os tatos são adquiridos em relação às condições internas, posteriormente nós falamos de uma forma similar quando experimentamos sensações e sentimentos similares, mesmo que respostas colaterais ou acompanhamentos públicos não estejam diretamente envolvidos. Por exemplo, falantes podem relatar uma dor ardente após arranhar a pele do joelho, ainda que nenhum fogão quente esteja envolvido. Em outros exemplos, falantes ou artistas apreensivos podem dizer "Eu sinto como se tivesse borboletas no estômago" antes de uma aula importante ou um recital, onde as sensações esvoaçantes nos seus estômagos se pareçam com aquelas de borboletas pousando sobre os seus braços.

Como um aparte, observamos que processos intimamente relacionados acontecem durante o treino de toalete, quando cuidadores ensinam os que estão sob seus cuidados como esvaziar, de formas socialmente aceitáveis, a bexiga ou o intestino cheios, dada a presença de

\footnotetext{
${ }^{1}$ Nota do tradutor: termo específico utilizado para alguém que finge uma doença.
}

estimulação privada. Por exemplo, cuidadores podem procurar alguma agitação que indique bexiga cheia, ou que a criança bebeu grandes quantidades de suco de fruta, para predispor modos socialmente aceitáveis de micção que podem então ser reforçados.

\section{Eventos Comportamentais Privados do Segundo Tipo: Comportamento Encoberto ${ }^{2}$}

Às vezes nós nos engajamos em comportamento encoberto, tipicamente comportamento operante encoberto. Comportamento encoberto é adquirido geralmente de forma aberta. Frequentemente, ele se torna encoberto com base em experiências ao longo das nossas vidas. Que experiências podem levar comportamento aberto a se tornar encoberto? Em alguns casos, o comportamento se torna encoberto porque a forma aberta é punida. Por exemplo, quando aprendemos a ler em voz alta. Entretanto, se outros ao nosso redor punirem nossa leitura em voz alta, por exemplo em uma biblioteca, nós mudaremos para a leitura silenciosa. Podemos também encobertamente explorar possibilidades alternativas, como qual carta jogar em um jogo de baralho ou qual peça mover em uma partida de xadrez. Ao fazê-lo evitamos consequências potencialmente punitivas de perder a jogada ou a peça. Em outras ocasiões, o comportamento se torna encoberto porque é oportuno. Por exemplo, frequentemente podemos resolver problemas simples de matemática "de cabeça" mais rápido do que escrevendo a solução com lápis e papel, e especialmente quando não temos lápis e papel. Um ponto importante é que o comportamento encoberto é executado pelo mesmo sistema de respostas que o comportamento aberto, apenas em escala reduzida. A esse respeito, considere a chamada "matemática mental". O termo é um equívoco. É uma matemática comportamental. A atividade consiste tipicamente em quebrar o problema de matemática em séries de passos menores que podem ser executados encobertamente sem a perda do controle de estímulos que frequentemente acompanha a estimulação encoberta.

Em alguns casos, a função do comportamento encoberto é contribuir para o controle discriminativo, como no "pensar" e no resolver problemas. Nós tipicamente entramos em contato com eventos comportamentais privados por meio de nossos sistemas nervosos proprioceptivo e possivelmente interoceptivo. A função discriminativa do comportamento encoberto, em última análise, não difere daquele do comportamento aberto, e comportamento encoberto não alcança nada além do que a forma aberta o faz, exceto a possibilidade de evitar a punição. Geralmente, mas não necessariamente, nosso comportamento encoberto é verbal. Casos especiais são processos perceptivos, como quando nossa história passada nos leva a imaginar visualmente a solução de um problema, como quando movemos uma peça num tabuleiro de xadrez. O ver condicionado de forma clássica

2 Nota do tradutor: na tradução em português de About Behaviorism os termos covert e overt foram traduzidos como oculto e manifesto. Optou-se pelas traduções encoberto e aberto considerando seu uso corrente por autores brasileiros. 
também pode ocorrer, como quando olhamos rapidamente um círculo que tem uma falha e é incompleto, mas o percebemos como completo porque os círculos que temos visto e com os quais temos experiência até aquele momento nas nossas vidas têm sido sempre completos. Finalmente, comportamento encoberto nem sempre ocorre. Mesmo quando ocorre, ele pode não influenciar o comportamento aberto. Quando ele ocorre e influencia o comportamento aberto, sua influência pode ser vista como um elo numa cadeia.

Em outros casos, o comportamento encoberto pode ser reforçador por si mesmo, com quando nós imaginamos ou fantasiamos sobre algum objeto favorito, evento, pessoa ou curso de ação. Um caso relacionado é a racionalização Freudiana, onde indivíduos fornecem uma razão após o fato para justificar suas ações. Ao fazê-lo, o indivíduo evita o desprazer de ações demonstravelmente irracionais, tanto quanto a possibilidade de ser punido por outros. Outro caso relacionado é o das tendências obsessivo-compulsivas, em que os indivíduos se convencem a realizar alguma ação porque temem o que acontecerá se eles não executarem a ação. Novamente, os indivíduos provavelmente se sentem melhor depois de dizerem ou talvez apenas ao começar a dizer essas coisas a si mesmos, tanto quanto eles se sentiriam se outra pessoa dissesse a mesma coisa a eles. A terapia é geralmente direcionada a corrigir essas formas problemáticas de eventos privados.

Frequentemente surge a questão de como nosso próprio comportamento pode ser um estímulo. A resposta é direta: assim como qualquer outro evento pode ser um estímulo. Para esclarecer essa questão vamos considerar um exemplo. Feche seus olhos. Agora levante um dedo ou dois, você escolhe. Mantenha seus olhos fechados. Quantos dedos você levantou? Agora pense em levantar um dedo ou dois, você escolhe, mas não levante o dedo de verdade. Quantos dedos você pensou em levantar? Seu comportamento de levantar seu(s) dedo(s) de verdade é um estímulo discriminativo - um evento, consequentemente uma ocasião - para uma resposta subsequente, neste caso seu relato verbal sobre quantos dedos você levantou. Podemos dizer a mesma coisa a respeito do seu comportamento de pensar em levantar seu dedo. Em cada caso, você estava em contato com seu comportamento, seja na forma aberta ou encoberta, através do seu sentido proprioceptivo-sinestésico, e também possivelmente seu sentido interoceptivo, ao invés da visão, som, toque, sabor e cheiro exteroceptivos. Exatamente o quão central (e.g. rudimentar, incipiente, fragmentária, inobservável a outros, como pensar em levantar seu dedo) em oposição a periférica (e.g. completamente executada, observável a outros, como levantar seu dedo de verdade) uma resposta deve ser para que um indivíduo esteja em contato com ela e para que ela exerça controle discriminativo sobre o comportamento subsequente depende de circunstâncias individuais. Sentir um espirro chegando é com certeza um exemplo suficientemente comum. Em casos excepcionais, matemáticos podem resolver problemas complicados ou gerar provas muito rapidamente baseados em propriedades incipientes de respostas encobertas. Programadores de computador habilidosos fazem o mesmo. Compositores podem criar uma partitura musical de formas similares. Novamente, essas habilidades dependem de uma história longa. A experiência consagrada "Aha!" ("Eureka!") pode ser entendida como outro exemplo de uma resposta a estágios incipientes de uma resposta.

\section{CONSCIÊNCIA}

Um tópico final é a consciência. Consciência é de fato outro tópico consagrado na história da psicologia. É frequentemente tomada na psicologia tradicional como sendo um tipo de fenômeno privado de outro domínio, tal como o domínio mental ou cognitivo, que medeia a relação entre circunstâncias ambientais como entrada (input) e comportamento como saída (output). Behavioristas radicais têm uma compreensão da consciência bastante diferente. Para behavioristas radicais, consciência significa responder com relação a si mesmo, onde as respostas são privadas ou públicas, verbais ou não-verbais.

Em algumas situações o responder é com relação às condições internas dos nossos corpos, como quando relatamos verbalmente nossas sensações e sentimentos. Quando respondemos a nós mesmos, nosso responder pode muito bem ser verbal. Quando é verbal, ele deve sua força à comunidade verbal. Por exemplo, a comunidade verbal pode nos perguntar como estamos nos sentimos. Os processos que estão envolvidos neste caso foram vistos anteriormente, quando explicamos como relatos verbais sobre condições internas se desenvolvem.

Como um aparte, observamos que cedo na história da psicologia alguns pesquisadores pensaram que os indivíduos poderiam relatar verbalmente cerca de 42.415 sensações diferentes. Behavioristas radicais acham que esse número é fantasioso por duas razões. Primeiro, nós não temos nervos suficientes indo para os lugares certos que nos permita discernir essa quantidade enorme de condições internas em nossos corpos, além de que se duvida que essa quantidade grande de condições possa mesmo ser produzida. Segundo, mesmo que tivéssemos nervos suficientes, a comunidade verbal não consegue reforçar as respostas precisamente o suficiente para gerar essas discriminações tão refinadas, como deve ser capaz de fazer com estimulações públicas como cores ou notas musicais.

Em outras ocasiões, o responder é com relação ao nosso comportamento passado, presente ou futuro provável e às circunstâncias das quais o comportamento foi, é ou provavelmente será função. A comunidade verbal também pode nos perguntar o que fizemos no passado, o que estamos fazendo agora e o que provavelmente faremos no futuro, e que contingências são responsáveis por tal comportamento. A comunidade verbal pode então reforçar através da aprovação de respostas socialmente razoáveis.

Quando respondemos com relação ao nosso próprio comportamento, o comportamento com relação ao qual estamos respondendo pode ser aberto ou encoberto, e as respostas que damos ao nosso próprio comportamento também podem ser abertas ou encobertas, verbais ou não 
verbais. Os processos que estão envolvidos nestes casos foram vistos anteriormente, quando explicamos como comportamento encoberto se desenvolve e nos influencia. $\mathrm{O}$ controle discriminativo que emerge daquele comportamento encoberto é uma característica crítica.

Estar consciente pode, portanto, ser entendido como comportamental e não mental em sua natureza e como um produto social. Novamente, responder abertamente com relação a nós mesmos não é uma medida de um estado mental inobservável da consciência. Ao invés disso, é o que a consciência sempre e somente significou, apesar das muitas outras maneiras perniciosas de como a psicologia tradicional concebe o seu significado. Consciência é um tópico importante porque nosso comportamento com relação a nós mesmos é importante para o autoconhecimento e o autogerenciamento. Se soubermos mais sobre nós mesmos, no sentido do que estamos sentindo, do que estamos fazendo e o porquê, poderemos gerenciar melhor nossas vidas e interagir mais efetivamente com características do nosso ambiente material e outras pessoas em nosso ambiente social.

\section{POR QUE OS BEHAVIORISTAS RADICAIS ARGUMENTAM EM FAVOR DE EVENTOS COMPORTAMENTAIS PRIVADOS?}

Behavioristas radicais não consideram um organismo como sendo literalmente vazio, não ignoram ou negam eventos dentro da pele e não permanecem restritos ao nível das relações observáveis envolvendo estimulação e respostas. Eventos comportamentais privados podem ser inegavelmente relevantes para uma compreensão de uma dada ocorrência de comportamento como uma ação em contexto, mesmo que eles sejam inacessíveis ou inobserváveis do ponto de vista dos outros. Como eventos reais, eles podem ser incluídos na compreensão do comportamento usando os mesmos termos e conceitos como eventos, variáveis e relações externas e observáveis.

A posição do behaviorista radical sobre os eventos comportamentais privados não é mentalismo nem behaviorismo metodológico. A posição não é mentalismo porque (a) as respostas são parte do domínio comportamental, não de um domínio mental; (b) as respostas são executadas pelos mesmos sistemas de respostas que as respostas abertas, apenas reduzidas em magnitude; e (c) ambos, a origem e os efeitos dos eventos comportamentais privados sobre comportamento subsequente são funcionalmente relacionados às circunstâncias ambientais. Assim, para os behavioristas radicais, eventos comportamentais privados são muito diferentes da ampla variedade de estados e processos mentais e cognitivos causais que a psicologia tradicional propõe como necessários para uma explicação.

Similarmente, a posição do behaviorista radical sobre os eventos comportamentais privados não é behaviorismo metodológico porque a posição do behaviorista radical fala diretamente sobre a possível relevância funcional dos eventos comportamentais encobertos, mesmo que eles sejam inobserváveis a outros. $\mathrm{O}$ behaviorismo radical não tenta obter concordância e fazer afirmações analíticas ou explicativas de fenômenos a partir de um domínio mental inobservável, cientificamente respeitável, apelando para dados observáveis em uma definição operacional. Desse modo, comportamento aberto não é uma medida do processo mental ou cognitivo do pensar. Ao invés disso, pensar é uma forma de comportamento em si e por si mesma, importante pela sua função discriminativa ou reforçadora. Sem dúvida, até que nossa tecnologia melhore e uma segunda pessoa possa acessar diretamente os (até então) eventos privados de uma primeira pessoa, do ponto de vista da segunda pessoa os eventos privados da primeira são uma inferência, mas para a primeira, os eventos privados não são inferência.

\section{QUAL É O STATUS CAUSAL DOS EVENTOS COMPORTAMENTAIS PRIVADOS?}

Qual é então o status causal dos eventos privados? Com relação ao primeiro tipo de evento comportamental privado - relatos verbais sobre sensações e sentimentos - as condições sentidas servem como formas de estimulação discriminativa para relatos verbais sobre elas. Entretanto, para propósitos analíticos, precisamos traçar a fonte do comportamento geralmente atribuída aos sentimentos e sensações no passado aos eventos ambientais, variáveis e relações que dão origem aos sentimentos e sensações, não parar no nível dos sentimentos e sensações em si mesmos.

Com relação ao segundo tipo de evento comportamental privado - comportamento encoberto esse comportamento é causal no sentido de que pode contribuir para o controle discriminativo sobre comportamento subsequente, por exemplo, através da sua participação como um elo numa cadeia de respostas estendida ao longo do tempo. Se ele realmente o faz, é uma questão empírica. Novamente, comportamento encoberto não ocorre automaticamente e necessariamente em todas as instâncias de comportamento. Quando ele ocorre, ele não influencia o comportamento subsequente automaticamente e necessariamente. Ao invés disso, o comportamento encoberto pode contribuir para controle discriminativo através das experiências dos indivíduos durante seu tempo de vida. Até que ponto ele realmente o faz depende, então, dessas experiências.

\section{SÍNTESE E CONCLUSÕES}

Concluindo, se não podemos explicar de uma maneira naturalística como aprendemos a falar sobre o que sentimos ou como aprendemos a pensar, a alternativa é algum tipo de explicação mentalista que damos, talvez de acordo com algum tipo de linguagem privada, mas isso não é uma explicação nem um pouco razoável. O conceito de eventos comportamentais privados oferece uma explicação científica abrangente baseada em princípios comportamentais aprofundados, ao invés de uma explicação baseada em ficções explanatórias de estados e processos mentais.

Termos e conceitos importantes: Problema da privacidade, eventos comportamentais privados, respostas colaterais, acompanhamentos públicos, propriedades 
coincidentes, generalização de estímulos, pensamento, resolução de problemas, função discriminativa de comportamento operante encoberto, função automaticamente reforçadora de comportamento operante encoberto, ver condicionado, ver operante.

\section{REFERÊNCIA}

Skinner B. F. (1953). Private events in a natural science. In B. F. Skinner, Science and Human Behavior (pp. 257-282). New York: Macmillan.

Submetido: $28 / 03 / 2018$

Aceito: $21 / 04 / 2018$ 